\title{
HUMANIZAÇÃO DA EQUIPE DE ENFERMAGEM NO PARTO: UM DIREITO QUE ASSISTE A PARTURIENTE
}

\author{
HUMANIZATION OF THE NURSING TEAM IN LABOR: \\ A RIGHT TO ASSIST THE PARTURIENT
}

\author{
Camila Teixeira de Carvalho Dias' \\ Érica Cristina do Nascimento Lopes ${ }^{2}$ \\ Marina Sarmento Braga Ramalho de Figueiredo ${ }^{3}$ \\ Rayla Borges Martins ${ }^{4}$ \\ Alridiany Ferreira Miranda ${ }^{5}$
}

\begin{abstract}
RESUMO
O presente estudo tem objetivo principal avaliar a humanização da assistência da enfermagem no parto. A pesquisa foi do tipo exploratório-descritiva, com abordagem quantitativa. A coleta de dados foi realizada mediante a aplicação de um questionário estruturado, contendo questões fechadas, que foram aplicados com 23 puérperas que haviam se submetido ao parto na Maternidade Cândida Vargas, localizada em João Pessoa-PB, onde foi aplicado em dias úteis, no período da tarde, no mês de setembro e outubro 2017. Verificou-se, uma predominância de puérperas faixa etária entre 18 a 25 anos, que possuíam ensino médio e eram solteiras. Verificou-se uma satisfação das puérperas em relação à assistência recebida, onde relataram que receberam uma assistência humanizada, tiveram o direito da presença do companheiro, houve o contato imediato entre mãe e bebê, a amamentação aconteceu logo após o parto, o cordão umbilical só foi cortado de 1 a 3 minutos após o nascimento, tiveram suas privacidades mantidas e, em nenhum momento ouviram palavras que as deixassem constrangidas. No entanto, foram identificadas algumas fragilidades, de maneira que a maioria delas não teve o direito de escolher a posição do parto e não oferecido líquidos no momento do parto.
\end{abstract}

Palavras-chave: Parto Humanizado. Humanização. Enfermagem.

\section{ABSTRACT}

The present study has the main objective to evaluate the humanization in nursing care at childbirth. The research was exploratory-descriptive, with a quantitative approach. Data collection was performed through the application of a structured questionnaire, containing closed questions, which were applied with 23 postpartum

1 Mestre em Enfermagem pela Universidade Federal da Paraíba (UFPB). Docente do Centro Universitário de João Pessoa (UNIPÊ). E-mail: camilatcs2@gmail.com

2 Bacharel em Enfermagem pelo Centro Universitário de João Pessoa (UNIPÊ). E-mail: erica_fisiol@hotmail.com

3 Graduanda em Enfermagem pelo Centro Universitário de João Pessoa (UNIPÊ). E-mail: marinasbraga@outlook.com

4 Graduanda em Enfermagem pelo Centro Universitário de João Pessoa (UNIPÊ). E-mail: raylabmartins@hotmail.com

5 Graduanda em Enfermagem pelo Centro Universitário de João Pessoa (UNIPÊ). E-mail: alridianyf.miranda@outlook.com

\section{INTER/SCIENTIA}

REVISTA INTERSCIENTIA | V. 7 | N. 1 | P. 181-199 | JAN-JUN/2019 
women who had undergone labor at the Cândida Vargas Maternity Unit, located in João Pessoa-PB, where it was applied on working days, at during the afternoon, in September and October 2017. There was a predominance of puerperae between 18 and 25 years old, who had high school and were single. There was a satisfaction of the puerperae in relation to the assistance received, where they reported that they received a humanized assistance, had the right of presence of the companion, there was the immediate contact between mother and baby, breastfeeding happened soon after the delivery, umbilical cord only was cut from 1 to 3 minutes after birth, had their privacies maintained and at no time did they hear words that would make them uncomfortable. However, some fragilities were identified, so that most of them did not have the right to choose the delivery position and not offered liquids at the time of delivery.

Keywords: Childbirth. Humanization. Nursing.

\section{INTRODUÇÃO}

Descrever que a mulher que decide pelo parto normal, espera por cuidado humanizado, pois ela sabe que o processo de parturição pode provocar experiências negativas. Contudo, para que esta impressão seja revertida, o modelo assistencial deve proporcionar um cuidado direcionado às suas necessidades e este cuidado deve ser aplicado também às rotinas e protocolos preestabelecidos do local do parto e aos profissionais, diretamente ligados à assistência ao parto (GONÇALVES et al., 2011).

Sabe-se que o nascimento de um filho é algo único para a vida dos pais, por isso necessita-se de uma assistência de qualidade e atenção voltada a mulher no momento do parto, garantindo a segurança, respeito e bem-estar (GOMES et al., 2014).

Existem diversas causas de insatisfações do modelo de assistência do parto convencional, sendo eles o atendimento despersonalizado, o emprego de procedimentos desnecessários, a falta de informações, de suporte emocional, de recursos de alívio da dor, e a comunicação interpessoal inadequada, causado frustrações em muitas mulheres, que buscam por um parto mais humanizado e sentir-se mais aliviadas (JAMAS; HOGA; TANAKA, 2011).

Em relação aos profissionais enfermeiros e os demais envolvidos na maternidade, é recomendado formação continuada para aperfeiçoar o conhecimento a respeito do parto humanizado, desta forma a assistência será mais abrangente, com a redução dos métodos invasivos, garantindo um menor número de riscos, permitindo que a parturiente tenha liberdade para efetivação do parto (FERREIRA et al., 2013). 
Na atualidade, pode-se ver o quanto ainda existe deficiência, no que diz respeito à assistência concedida à mulher no momento do parto. Assistência essa que é direito da mulher, sendo necessário que seja de forma humanizada.

Inúmeras mulheres ainda relatam traumas, por situações vivenciadas no parto, por falta de humanização da equipe, tendo sido fundamental a abordagem desse tema, levando-se em conta a importância da humanização no trabalho de parto.

Sendo assim, surgiu o seguinte questionamento para nortear o estudo: a enfermagem está assistindo a mulher, no parto, de maneira humanizada?

Dessa maneira, o presente estudo teve com objetivo principal: avaliar a humanização da assistência de enfermagem no parto.

\section{OBJETIVOS}

\section{OBJETIVO GERAL}

- Avaliar a humanização da equipe de enfermagem no parto.

\section{OBJETIVOS ESPECÍFICOS}

- Buscar informações das puérperas a respeito de como foi a assistência de enfermagem no parto;

- Analisar o grau de satisfação dessas mulheres em relação ao atendimento no parto;

- Abordar a necessidade dos profissionais de enfermagem adotarem práticas humanizadas na atenção à parturiente;

- Sensibilizar as parturientes sobre a necessidade de reivindicarem os seus direitos, no que tange a uma assistência humanizada.

\section{REVISÃO BIBLIOGRÁFICA}

\section{A ESCOLHA DO PARTO}

A escolha do parto se inicia no pré-natal, pois o mesmo permite uma comunicação entre a gestante e profissional, ocorrendo uma troca de informações pertinentes, sensibilizando a mulheres sobre o seu direito de receber uma assistência humanizada, independentemente do tipo de parto escolhido. Os partos mais conhecidos são o parto normal e o parto cesáreo. 
O parto normal é um parto que respeita a fisiologia da mulher, sendo ele então o convencional do ato de parir, já o parto cesáreo é um procedimento cirúrgico em que ocorre retirada, ou seja, a expulsão do bebê do útero de sua mãe, sem ao menos saber se esse é o momento que ele quer nascer.

A Organização Mundial de Saúde (OMS) vem lançando diretrizes com foco na humanização e desmedicalização do parto, ou seja, desconstruindo a ideia de que o médico é responsável pela escolha do parto. Essas diretrizes oferecem a mulher uma participação direta a respeito da escolha da assistência que lhes serão prestados (WHO, 2015).

Conforme o crescimento de partos em um ambiente hospitalar, a escolha do parto cirúrgico vem prevalecendo pelo simples fato de se tratar de um procedimento mais rápido, esquecendo que o parto cirúrgico é um procedimento para salvar a vida da mãe e RN e não algo a ser escolhido por motivos irrelevantes.

O Relatório das Diretrizes Nacional de Assistência ao Parto Normal, com o propósito de aplicar as seguintes diretrizes, releva que nas primíparas o parto dura em média 8 horas onde em poucos casos estende-se a mais de 18 horas. Já no que refere as multíparas, dura em media 5 horas, podendo essa percorrer por um período não mais de 12 horas (BRASIL, 2016).

Sendo assim, as informações expressadas acima potencializam ainda mais a escolha do parto cirúrgico, por se tratar de um procedimento rápido, onde a sua realização dá a entender que o médico poderá assistir um número maior de puérperas.

De acordo com a Word Health Organization (WHO) (2015), o parto cirúrgico deveria corresponder a $15 \%$ dos casos, mediante o risco que o parto normal traga para a mãe e o RN.

Mas, infelizmente a escolha do parto cirúrgico também ocorre a pedido da parturiente, onde a mesma, por não receber informações suficientes dos profissionais que the assistiram durante a gestação, acabam sentindo medo do parto natural, compreendendo o mesmo de maneira equivocada, como um momento de estágio prolongado, acompanhado de dores, de tal forma que ela prefere optar por um método que considere mais rápido, não sendo necessariamente o mais indicado.

A Organização Mundial de Saúde (OMS) alertou que o aumento do índice de partos cesáreos, em todo o mundo, vem crescendo nos últimos 20 anos, transfigurando o parto cirúrgico em uma "epidemia" (WHO, 2015).

Trata-se de um grave problema de saúde pública, sendo necessário uma reflexão, por parte de todos os profissionais da área de saúde.

Existem indicações para a cesárea e são fundamentadas ao estado e condições materno-fetais. Onde a sua definição tem como objetivo garantir êxito do nascimento em casos em que a via normal é impedida (CUNNINGHAM; LEVENO; BLOOM, 2010). 
Isto é, o parto cesariano só deve ser realizado mediante o risco que a mãe e o RN estejam correndo com a realização do parto fisiológico, pois como sabemos existem ocorrências clínicas que levam à realização do parto cirúrgico.

\section{PARTO HUMANIZADO}

O parto é um acontecimento memorável, transbordado por sensações de grande significado, evento assinalado pelo recebimento de um novo ser na vida da mulher e sua família.

Nagahama e Santiago (2011) relevam que o conceito do parto humanizado é bastante variado, mas que por essa luta existe um movimento que defende e respeita a singularidade da mulher, de forma que a mantém como protagonista, assegurando também a adequação da assistência no que diz respeito à cultura, crença, valores e pluralidade de opiniões. Desse modo, humanizar o parto é respeitar e garantir que todos os aspectos espirituais, psicológicas e biológicas sejam atendidos.

Sendo assim, percebe-se que o parto humanizado respeita totalmente a individualidade da mulher e todos os aspectos que the envolvem.

Parto humanizado é o respeito dado à mulher e sua família, nesse momento a mulher necessita de assistência e não de intervenções, é aguardar de forma sadia e harmônica o nascimento, acreditando que o parto normal é fisiológico, de maneira que nem sempre necessita de intervenções, conduzindo a mulher a ser protagonista do seu parto (BRASIL, 2014).

De acordo com o mesmo autor citado anteriormente, ouvir a mulher é respeitar a sua individualidade, sempre a informando sobre os procedimentos a serem realizados na assistência, garantindo e facilitando a presença do acompanhante em todo momento da assistência, no sentido de passar segurança e tranquilidade, proporcionando um ambiente aconchegante. Prestando a assistência de evidencias cientificas e permitindo o contato imediato entre mãe e RN.

A humanização do parto tem como objetivo atribuir à mulher um sentimento de confiança no momento do parto. Observa-se que assistência humanizada faz com que a mulher se sinta capaz em exercer a sua mais nova função social. Esse momento vivido proporciona a sensibilização e interesse pela sociedade, fortalecendo-a socialmente. Estudos mostram que o modelo de uma assistência humanizada proporciona benefícios físicos e psicológicos. Parto humanizado consiste em deixar a mulher ter controle total de suas ações, ao qual venha de forma íntima e ativa a contribuir nas decisões sobre o seu próprio cuidado. Portanto, a equipe atua apenas como facilitadora do processo de parturição (GONÇALVES et al., 2011). Ou seja, para que ocorra a realização do parto humanizado, o enfermeiro deve assistir cada mulher de forma individual, sempre adequando a assistência e 
aplicando boas práticas, nunca deixando de lado os sentimentos dos envolvidos nesse momento.

A legislação de número 7.498 de 25 de junho de 1986, que determina a regularização do exercício da enfermagem, apresenta em seu Artigo 11 que o enfermeiro obstetra é membro da equipe de saúde, com isso ele deve desempenhar todas as atividades de enfermagem, como também terá que fornecer assistência de enfermagem a gestantes, parturientes e puérperas, participando do processado trabalho de parto e parto (BRASIL, 1986).

$O$ processo de enfermagem, como um instrumento legal do enfermeiro para desenvolvimento de suas ações, no cotidiano de trabalho, constitui-se numa estratégia importante no planejamento e implantação das ações de cuidado aos sujeitos por eles atendidos, com aplicação de tecnologia e de conhecimento científico (ZUSE; BRIGO; SILVA, 2010).

Sendo assim, podemos refletir acerca da importância de resgatar o entendimento de que o parto normal é um momento fisiológico, onde a enfermagem é uma peça fundamental nesse resgate. Como foi pontuado acima, diretrizes foram feitas com base na atuação do enfermeiro obstétrico, com enfoque na diminuição de procedimentos invasivos.

Mas não podemos deixar de ressaltar que para ocorrer um resultado satisfatório, se faz necessário uma sensibilização de toda a equipe de saúde, pois a assistência requer um envolvimento multidisciplinar, no que se refere a assistência humanizada.

Cagnim (2014) ressalta que para uma pessoa conduzir um trabalho de parto e parto se faz necessário qualificação para realizar intervenção existentes, tento a agilidade para iniciar o tratamento de forma imediata e correspondente a necessidade da mãe e do RN como também no contexto particular.

Dessa forma, é necessário que esses profissionais estejam buscando se atualizar, buscar conhecimentos e se especializar, para melhor assistir essas mulheres, atendendo todas as suas necessidades e tendo uma visão holística do ser.

\section{METODOLOGIA}

Foi realizada uma pesquisa do tipo exploratória-descritiva, com abordagem quantitava. No que refere ao instrumento de coleta de dados foi elaborado um questionário estruturado, contendo questões fechadas, que foi aplicado junto à puérperas presentes na maternidade analisada. Estes foram aplicados em dias úteis, no período da tarde, no mês de setembro e outubro de 2017.

O local de pesquisa correspondeu à Maternidade Cândida Vargas, localizada em João Pessoa, especificamente nas enfermarias, tendo sido escolhida por ser uma maternidade referência em João Pessoa- PB. 
Emrelaçãoà população, essa correspondeu a todas as mulheres que estavam recebendo assistência na maternidade. No entanto, a amostra correspondeu a 23 puérperas, ao qual seu parto foi realizado na maternidade em questão e tiveram seu parto realizados pelas enfermeiras obstétricas, correspondendo a $50 \%$ da população de puérperas alojadas nas enfermarias, tendo sido selecionada a amostra por meio do método não probabilístico por conveniência.

Como critérios de inclusão, foi definido que para que as participantes integrassem o estudo seria necessário que: fossem maiores de 18 anos; alfabetizadas tivessem realizado o parto pela enfermeira obstétrica em no máximo 45 dias naquela maternidade, recebendo assistência nas enfermarias.

Como critérios de exclusão, foi definido que estariam fora da pesquisa as mulheres que fossem menores de 18 anos, não fossem alfabetizadas e não tivessem realizado o parto com a enfermeira obstétrica, em no máximo 45 dias naquela maternidade.

A análise dos dados foi realizada com enfoque no método quantitativo, de maneira que os dados foram apresentados através de gráficos e tabelas, sendo utilizado como ferramenta o software Windows Microsoft Word.

A coleta de dados foi iniciada mediante a aprovação do projeto de pesquisa pelo Comitê de Ética, o encaminhamento de ofício da coordenação do Curso para a instituição, local da pesquisa, comunicando a intenção da mesma, além da assinatura das puerperas no que se refere ao Termo de Consentimento Livre e Esclarecido (TCLE), levando em consideração a Resolução 466/2012.

As despesas da pesquisa foram de responsabolidade exclusiva da pesquisadora, por su vez o Centro Universitario de João Pessoa disponibilizou a biblioteca para buscas de referências, computadores e conectivos, assim como orientador e a banca examinadora.

\section{RESULTADOS E DISCUSSÃO}

Para fins de demonstração, os dados analisados foram apresentados através de gráficos, para que seja possível estabelecer uma melhor discussão a respeito dos mesmos.

Em relação ao Questionário aplicado com puérperas que tenham tido o parto realizado por enfermeira obstétrica, temos os seguintes dados:

\section{CARACTERIZAÇÃO DA AMOSTRA}

A amostra compreende a distribuição das 23 (vinte e três) puérperas no que se refere à idade, escolaridade e estado civil. 


\section{IDADE, ESCOLARIDADE E ESTADO CIVIL}

Observa-se que a maioria das parturientes, ou seja, 74\% estavam na faixa étaria dos 18-25 anos ( $n=17)$, seguido da faixa etária entre 26 a 35 anos correspondendo a $13 \%$ ( $n=03$ ), seguido de $13 \%$ correlacionado à faixa etária entre 36 a50 anos ( $n=03$ )

Esse resultado está de acordo com a afirmação feita por Delpisheh et al. (2008), que diz que apesar de mulheres mais maduras apresentarem vantagens para uma gestação, como uma maior estabilidade financeira, muitas mulheres ainda optam por engravidarem mais cedo, pois acreditam que estão expostas a um maior risco para abortamentos espontâneos e induzidos, maior risco para mortalidade perinatal, baixa vitalidade do recém-nascido, baixo peso ao nascer, parto prétermo, além do risco para o feto nascer pequeno para a idade gestacional.

Ainda de acordo com o mesmo autor citado anteriormente, vale ressaltar que as alterações mais frequentes de peso do recém-nascido nestas mulheres incluem tanto os casos de macrossomia, quanto os de peso pequeno para a idade gestacional. A Tabela 1 mostra os dados sociodemográficos.

Tabela 1: Dados sociodemográficos

\begin{tabular}{|c|c|c|}
\hline ldade & $\begin{array}{l}74 \%-18 \text { a } 25 \text { anos } \\
13 \%-26 \text { a } 35 \text { anos } \\
13 \%-36 \text { a } 50 \text { anos }\end{array}$ & \multirow{3}{*}{$n=23$} \\
\hline Escolaridade & $\begin{array}{l}39 \% \text { - Ensino fundamental completo } \\
48 \% \text { - Ensino médio completo } \\
09 \% \text { - Ensino superior completo } \\
04 \% \text { - Superior completo Incompleto }\end{array}$ & \\
\hline Estado Civil & $\begin{array}{l}39 \% \text { - Solteiro } \\
35 \% \text { - Casado } \\
26 \% \text { - União Consensual } \\
00 \% \text { - Viúva }\end{array}$ & \\
\hline
\end{tabular}

Fonte: Dados da Pesquisa. João Pessoa - PB, Setembro e Novembro, 2017.

Em relação à escolaridade, houve uma prevalência de mulheres com ensino médio completo, ou seja, $48 \%(n=11)$, enquanto $39 \%(n=9)$ possuíam o ensino fundamental completo, $9 \%(n=2)$ possuíam o ensino superior completo e $4 \%(n=1)$ possuíam o ensino superior incompleto.

Portanto, pode-se perceber que os dados estão de acordo com a afirmação feita por Andrade (2012) que diz que no Brasil, houve uma mudança significativa na oferta da educação a partir dos anos 90, ocorrendo uma universalização do ensino fundamental, o fortalecimento do ensino médio e também do ensino superior, triplicando o número de alunos matriculados. Entretanto, apesar desse crescimento, o percentual de acesso dos jovens ao ensino superior ainda é muito limitado.

Sendo assim, isso poderia justificar um número tão pequeno de mulheres jovens, que estavam inseridas no ensino superior, na pesquisa.

No que se refere ao estado civil, a pesquisa revelou que a maioria das participantes da pesquisa, ou seja, 39\% ( $n=09)$ eram solteiras, seguidas de $35 \%$ ( $n=$

\section{INTER SCIENTIA}

REVISTA INTERSCIENTIA | V. 7 | N. 1 | P. 181-199 | JAN-JUN/2019 
08) correlacionado as casadas, onde mostrou que a união consensual corresponde a $26 \%(n=06)$, explanando então que $00 \%(n=0)$ é referente as viúvas.

Dessa forma, esses dados estão de acordo com o que diz IBGE (2017), de que em 10 anos, o Brasil ganhou 1,1 milhão de famílias formadas por mães solteiras, o que é um número bastante impactante, uma vez que de acordo com o Instituto Brasileiro de Geografia e Estatística (IBGE), em 2005, o país apresentava um índice de 10,5 milhões de famílias de mulheres sem cônjuge e com filhos, morando ou não com outros parentes, porém a partir de 2015, os mais recentes do instituto, apontam 11,6 milhões arranjos familiares.

Ainda de acordo como autor citado anterior, embora tenha ocorrido um aumento no número absoluto, a representatividade das mães solteiras caiu de $18,2 \%$ para 16,3\%, neste período. Isso se deve ao fato de existir outros tipos de família, a exemplo daquelas de casais sem filhos e as unipessoais, estas cresceram de maneira mais proporcional.

Sendo assim, isso pode justificar a prevalência de mulheres solteiras, na pesquisa.

\section{SATISFAÇÃO NA ASSISTÊNCIA DE ENFERMAGEM AO PARTO}

No que se refere ao item 4, as parturientes ( $n=23$ ), responderam ao seguinte questionamento: "Você ficou satisfeita com a assistência de enfermagem, no parto?", conforme apresentado no Gráfico 1:

Gráfico 1: Distribuição das respostas dos participantes do estudo (N=23), de acordo com o questionamento.

\section{Satisfação com a assistência de enfermagem}
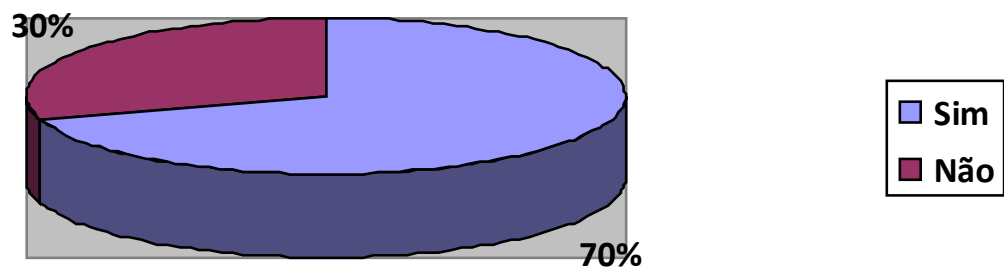

Fonte: Dados da Pesquisa. João Pessoa - PB, Setembro e Novembro, 2017

De acordo com os dados acima apresentados, podemos perceber que a maior parte das mulheres, ou seja, $70 \%(n=16)$ das puérperas responderam que ficaram satisfeitas com a assistência recebida no parto, onde $30 \%$ ( $n=7)$ delas mostraram a insatisfação com a assistência.

De acordo com Almeida, Gama e Bahiana (2015), o enfermeiro deve atuar baseando a sua assistência no ato de cuidar, de maneira a garantir conforto e segurança para a parturiente, sendo fundamental que esta mulher se sinta satisfeita 
com essa assistência, pois isso irá torna-la mais segura com o momento, deixando lembranças positivas a respeito da experiência.

\section{CONSIDERA TER RECEBIDO ASSISTÊNCIA HUMANIZADA}

No que se refere ao item 5, as parturientes $(n=23)$, responderam ao seguinte questionamento: "Assistência humanizada é o atendimento que garante os direitos da mulher e da família de serem acolhidos e tratados com educação, de serem respeitados como cidadãos, de serem informados sobre o diagnostico e o tratamento, tendo o direito de questionar e de aceitar ou não as decisões da equipe de saúde. Sendo assim, considera que recebeu cuidados de enfermagem recebidos correspondem a uma assistência humanizada?", conforme apresentado no Gráfico 2:

Gráfico 2: Distribuição das respostas dos participantes do estudo ( $N=23)$, de acordo com o questionamento.

\section{Assistência Humanizada}

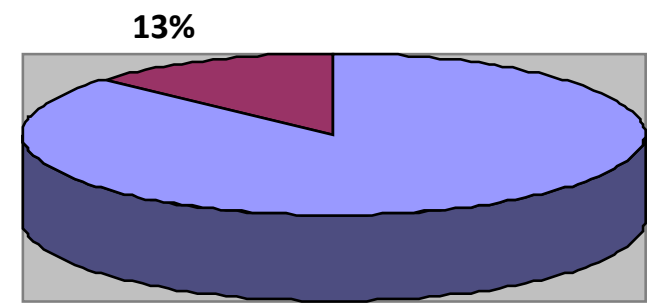

O gráfico acima apresentado revela que a maior parte das participantes, ou seja, $87 \%$ ( $n=20$ ) recebeu uma assistência humanizada, número esse positivo, por outro lado $13 \%(n=3)$ dessas mulheres revelam o não recebimento de uma assistência humanizada.

Essa afirmação está de acordo com o que diz Gonçalves et al. (2011), que a assistência humanizada tem por objetivo promover assistência integral, de forma que respeita e atende a parturiente no âmbito espiritual, psicológico, biológico, fazendo com que o parto seja mais fisiológico, por meio da diminuição de intervenções desnecessárias e na inclusão de práticas que podem diminuir o desconforto emocional e físico. 


\section{DIREITO DA PRESENÇA DO COMPANHEIRO (A) NA HORA DO PARTO}

No que se refere ao item 6, as parturientes ( $n=23)$, responderam ao seguinte questionamento: "Permitiram que o seu companheiro (a) estivesse presente durante o trabalho de parto?", conforme apresentado no Gráfico 3:

Gráfico 3: Distribuição das respostas dos participantes do estudo (N=23), de acordo com o questionamento.

\section{Presença do companheiro (a) no Parto}

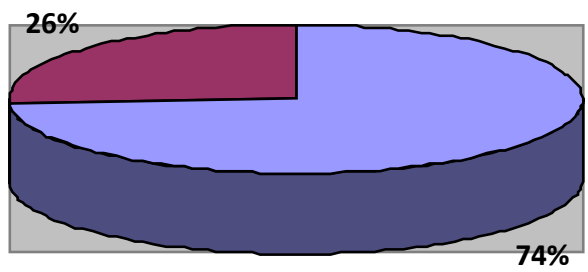

Fonte: Dados da Pesquisa. João Pessoa - PB, Setembro e Novembro, 2017

Percebe-se que a maioria das participantes, ou seja, 74\% ( $n=17$ ) das parturientes tiveram o direto da presença do companheiro no parto, porém $26 \%$ $(n=6)$ relataram não ter tido direito a ter o seu companheiro no momento do parto.

Essa afirmação está de acordo com o que diz MPPE (2015), de que a Lei $n^{\circ}$ 11.108, de 7 de abril de 2005 dá o direito a toda mulher de ter um acompanhante, em todo momento de sua estadia no meio hospitalar, sendo ele privado ou público.

Silva et al. (2014) revela que a presença do pai no momento do parto resulta de forma satisfatória na evolução do parto, pois devido a sua presença a mulher se sente segura. Essa presença estreita e fortalece os sentimentos de pai para com o RN.

\section{CONTATO IMEDIATO COM O RN}

No que se refere ao item 7 , as parturientes ( $n=23)$, responderam ao seguinte questionamento: "Logo após o Nascimento do bebê, a senhora teve contado com a criança ou simplesmente levaram a mesma imediatamente, para receber os cuidados?", conforme apresentado no gráfico 4.

Conforme os dados abaixo, podemos perceber que a maior parte delas, ou seja, $91 \%$ ( $n=21)$ tiveram o contato imediato com seu bebê, porém $9 \%(n=2)$ delas não tiveram esse direito.

Esses dados estão de acordo com o que diz Brasil (2014) o contato pele a pele logo após o nascimento, em temperatura ambiente de $26^{\circ} \mathrm{C}$, diminui o risco 
de hipotermia no RN a termo com respiração espontânea, sem existir a necessidade de ventilação, desde que seja devidamente aquecido. Os cuidados de rotina na sala de parto apenas devem ser iniciados após ter sido assegurado o ao bebê, a sua mãe e a seu pai, caso este esteja presente, um primeiro encontro seguro e protegido.

Gráfico 4: Distribuição das respostas dos participantes do estudo (N=23), de acordo com o questionamento.

\section{Contato imediato com o RN após o parto}

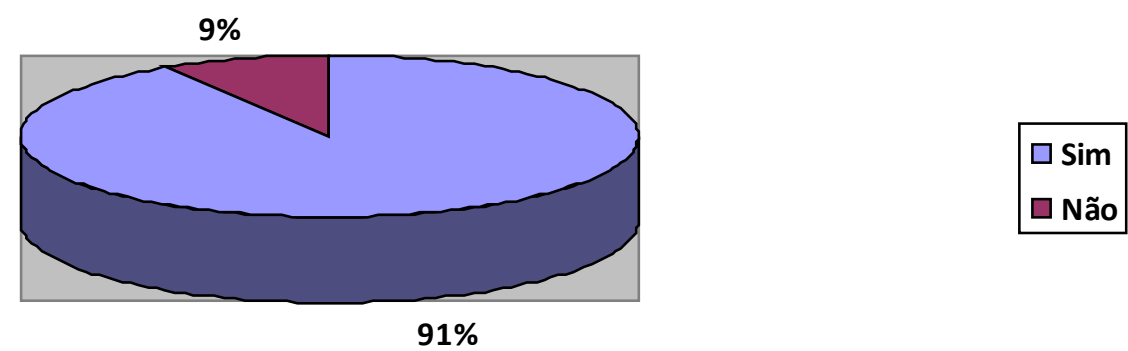

Fonte: Dados da Pesquisa. João Pessoa - PB, Setembro e Novembro, 2017

\section{AMAMENTAÇÃO LOGO APÓS O PARTO}

No que se refere ao item 8 , as parturientes ( $n=23)$, responderam ao seguinte questionamento: "Teve a oportunidade de amamentar seu filho logo após o parto?", conforme apresentado abaixo:

Gráfico 5 - Distribuição das respostas dos participantes do estudo (N=23), de acordo com o questionamento.

\section{Amamentação logo após o parto}

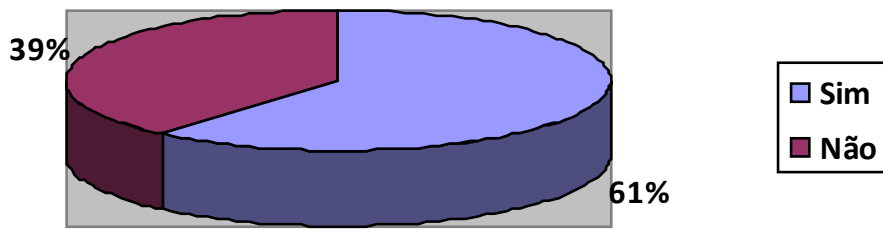

Fonte: Dados da Pesquisa. João Pessoa - PB, Setembro e Novembro, 2017

Podemos perceber que a maioria das mulheres, ou seja, $61 \%(n=14)$ das mulheres amamentaram logo após o parto, e 39\% (n=09) delas não tiveram a oportunidade de amamentar logo após o parto.

Victora et al. (2016) a amamentação imediata favorece uma eficiente sucção e estimula os impulsos inativos onde ressalta que a amamentação protege 
o RN de desenvolver patologias como diarreia, infecções respiratórias, otite média aguda, rinite alérgica, má oclusão dentária, com melhores resultados quanto a saúde bucal, reduz a probabilidade de sobrepeso, obesidade, diabetes tipo 2, alta performance em testes de inteligência na infância e adolescência e quanto mais cedo essa amamentação for iniciada, melhor.

\section{COMENTÁRIOS DESAGRADÁVEIS POR PARTE DA EQUIPE DE ENFERMAGEM}

No que se refere ao item 9, as parturientes ( $n=23)$, responderam ao seguinte questionamento: "Voce escutou algum comentário desagradável, por parte da equipe de enfermagem, que lhe deixou constrangida?", conforme apresentado no gráfico 6:

Gráfico 6: Distribuição das respostas dos participantes do estudo (N=23), de acordo com o questionamento.

\section{Constrangimento com comentários desagradáveis no parto}
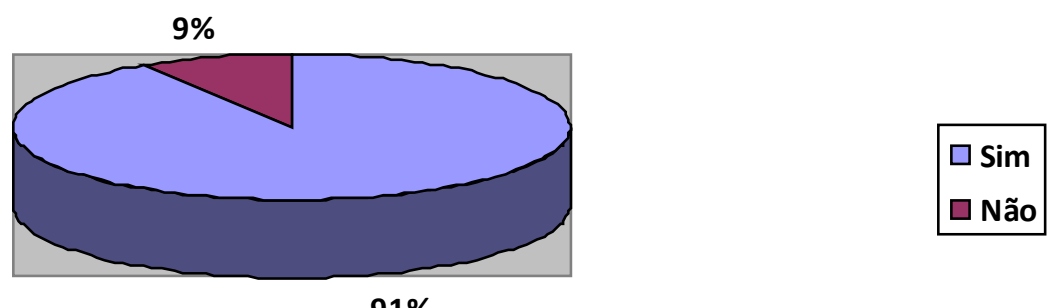

$91 \%$

Fonte: Dados da Pesquisa. João Pessoa - PB, Setembro e Novembro, 2017

O gráfico acima destaca que $91 \%(n=21)$ das puérperas não ouviu, por parte da equipe de enfermagem, palavras que a levassem a se sentirem constrangidas, porem 9\% ( $n=02)$ relatou que ouviram palavras desagradáveis.

Essa afirmação é favorável ao que diz MPPE (2015), que a verbalização de palavras à parturiente é considerada violência obstétrica, onde também enfatiza que a violência também pode partir de forma física, psicológica e até sexual. Essas atitudes podem gerar ações administrativa, civil e penal para os profissionais.

\section{O CORDÃO UMBILICAL FOI CORTADO MINUTOS APÓS O PARTO}

No que se refere ao item 10, as parturientes $(n=23)$, responderam ao seguinte questionamento: "O cordão umbilical da criança foi cortado imediatamente após o nascimento do bebê ou eles esperaram alguns minutos?", conforme apresentado no gráfico 7. 
Gráfico 7: Distribuição das respostas dos participantes do estudo (N=23), de acordo com o questionamento.

\section{Corte do cordão umbilical do RN após alguns minutos}
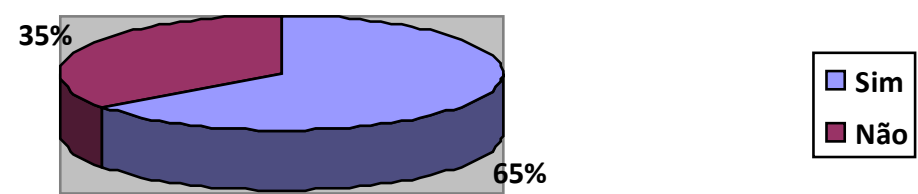

Fonte: Dados da Pesquisa. João Pessoa - PB, Setembro e Novembro, 2017

Conforme os dados, a maior parte das mulheres, ou seja, $65 \%(n=15)$ relataram que os bebês tiveram o corte do cordão umbilical após alguns minutos do parto, no entanto $35 \%$ ( $n=08$ ) tiveram o corte do cordão umbilical imediatamente após o parto.

Essa afirmação está de acordo com o que diz Salari et al. (2014), a clampagem do cordão umbilical indica o término da circulação feto-placentária, todavia, nos primeiros minutos após o parto ainda ocorre a passagem de sangue para o bebê, a chamada transfusão placentária, sendo necessário que o profissional espere cerca de 3 minutos para realizar o corte, isso poderá trazer benefícios ao bebê, como prevenção da anemia infantil, diminuição da enterocolite necrosante, da hemorragia intraventricular, da sepse infantil e redução da necessidade de transfusões de sangue.

\section{Direito na escolha da posição do parto}

No que se refere ao item 11, as parturientes $(n=23)$, responderam ao seguinte questionamento: "Você teve o poder de escolher a posição do parto?", conforme apresentado no gráfico 8.

Gráfico 8: Distribuição das respostas dos participantes do estudo (N=23), de acordo com o questionamento.

\section{Dire ito na escolha da posição de parto}

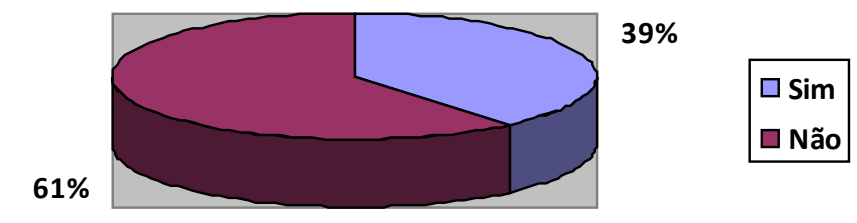

Fonte: Dados da Pesquisa. João Pessoa - PB, Setembro e Novembro, 2017

\section{INTER SCIENTIA}

REVISTA INTERSCIENTIA | V. 7 | N. 1 | P. 181-199 | JAN-JUN/2019 
De forma alarmante o gráfico acima sinaliza que $61 \%$ ( $n=14)$ das parturientes não tiveram a autonomia na escolha da posição do parto, enquanto 39\% (n=09) vivenciaram essa escolha.

Essa afirmação vai contra o que diz Brasil (2014), em metanálise incluindo 22 estudos randomizados controlados, com 7.280 mulheres, a utilização de qualquer posição vertical ou lateral comparado com a posição supina no segundo estágio do parto, esteve relacionado à diminuição da duração e do relato de dor grave nesse estágio, pequena diminuição no número de partos assistidos instrumentalmente e menor anormalidades nos padrões de frequência cardíaca fetal.

Sendo assim, faz-se necessária uma reflexão mais profunda acerca desse dado.

\section{INGESTA DE LÍQUIDOS DURANTE O PARTO}

No que se refere ao item 12, as parturientes (n=23), responderam ao seguinte questionamento: "A equipe de enfermagem lhe ofereceu líquidos durante o parto?", conforme apresentado no gráfico 9.

Oráfico evidencia que para $70 \%(n=7)$ das parturientes não foi ofertado líquido no momento do parto e para $30 \%$ delas o líquido foi oferecido.

Gráfico 9: Distribuição das respostas dos participantes do estudo (N=23), de acordo com o questionamento.

\section{Ingesta de líquidos durante o parto}
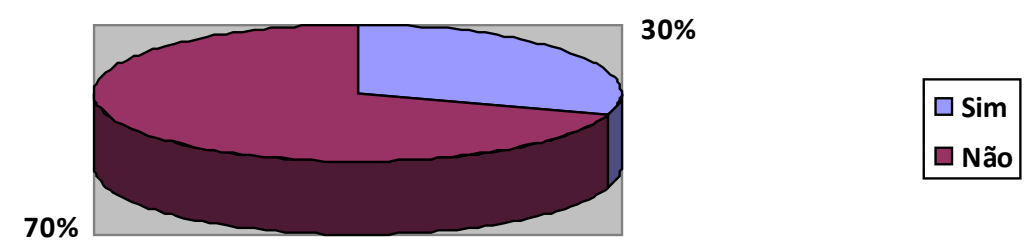

Fonte: Dados da Pesquisa. João Pessoa - PB, Setembro e Novembro, 2017

Essa afirmação vai contra o que diz MPPE (2015), que de acordo com a OMS, o trabalho de parto exige grandes quantidades de energia. Tendo em vista que não se pode prever a sua duração, a parturiente precisa repor as fontes de energia, objetivando garantir o bem-estar fetal e materno. Sendo assim, em uma gestante de risco habitual, com pouca chance de necessitar de anestesia geral, a ingestão de líquidos e alimentos leves deve ser permitida e estimulada.

Além disso, já foi comprovado que a ingestão de alimentos líquidos ou sólidos leves no trabalho de parto não aumenta o risco de complicações. Muitos locais ainda proíbem ou não ofertam à parturiente, por medo de aspiração de conteúdo estomacal durante uma anestesia, o que apenas se aplica para mulheres com risco 
habitual, que farão uso de anestesia geral (BRASIL, 2014). Portanto, trata-se de um dado negativo, sendo necessária uma reflexão.

\section{PRIVACIDADE ASSEGURADA}

No que se refere ao item 13, as parturientes $(n=23)$, responderam ao seguinte questionamento: "Considera que sua privacidade foi assegurada, no parto?". Conforme mostrado no gráfico 10.

Conforme dados $87 \%(\mathrm{n}=20)$ das puérperas tiveram a sua privacidade assegurada, onde para $13 \%(n=03)$ delas não foi assegurada a privacidade no momento do parto.

Essa afirmação está de acordo com o que diz Brasil (2015), que corresponde a uma prática humanizada, no parto, garantir a privacidade da mulher e seu acompanhante no parto, a fim de garantir o bem-estar desta mulher, para que se sinta segura durante o parto.

Sendo assim, corresponde a um fator bastante positivo.

Gráfico 10: Distribuição das respostas dos participantes do estudo (N=23), de acordo com o question

\section{Privacidade assegurada}
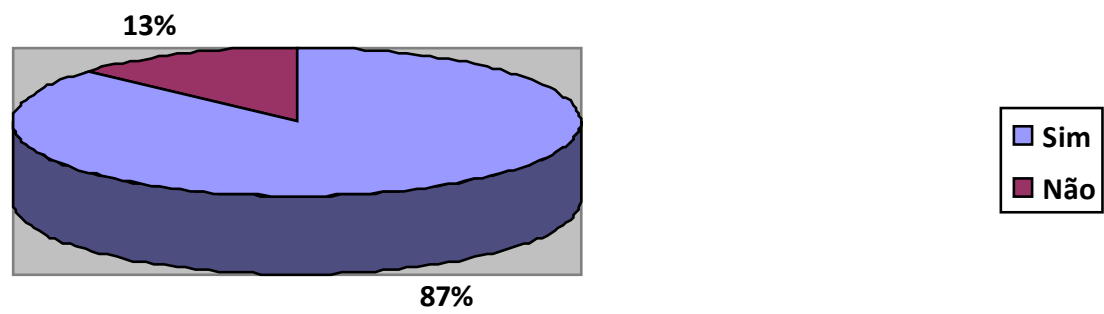

Fonte: Dados da Pesquisa. João Pessoa - PB, Setembro e Novembro, 2017

\section{CONSIDERAÇÕES FINAIS}

Mediante pesquisa desenvolvida, no percuso de toda a elaboração deste artigo, foi possível observar o quanto é necessária uma assistência humanizada por parte dos enfermeiros. Onde vale ressaltar a importância do olhar e prática humanizada por se tratar de uma maternidade escola, tendo ela uma responsabilidade muito grande na construção de boas práticas dos enfermeiros em formação.

Ao analizar os dados sociodemográficos, verificou-se uma predominância de puérperas na faixa etária entre 18 a 25 anos, que possuíam ensino médio e eram solteiras. Estes dados podem ser explicados tomando como base a literatura pertinente, onde encontram-se afirmações relevantes, a respeito desses fatos. 
Referente às questões norteadoras do estudo, os resultados foram bastante positivos. Verificou-se uma satisfação das puérperas em relação à assistência recebida, por parte da equipe de enfermagem, onde afirmaram que receberam uma assistência humanizada; tiveram o direito da presença do companheiro no momento do parto; existiu o contato imediato entre mãe e bebê; a amamentação foi iniciada logo após o parto; ocorreu a espera de 1 a 3 minutos para o corte do cordão umbilical; tiveram a sua privacidade garantida e em nenhum momento ouviram palavras que as deixassem constrangidas.

No entanto, foram identificadas algumas fragilidades, de maneira que a maioria das puérperas relataram que não tiveram o direito de escolher a posição do parto e não foi oferecido líquidos no momento do parto.

É necessário que ocorra a sensibilização das enfermeiras obstétricas, em relação ao direito da parturiente de escolher a posição do parto e da importância de ofertarem líquidos no momento do parto. Torna-se fundamental investir em capacitações no que se refere ao parto, de maneira que os profissionais possam se atualizar e se capacitar a respeito das novas práticas indicadas no parto, para garantir a humanização da assistência, nesse momento que é tão especial para a mulher.

\section{REFERÊNCIAS}

ALMEIDA, O. S. C.; GAMA, E. R.; BAHIANA, P. M. Humanização no parto: a atuação dos enfermeiros. Revista Enfermagem Contemporânea. v.4, n.1, p. 79-90, 2015.

ANDRADE, C. Acesso ao ensino superior no Brasil: equidade e desigualdade social. São Paulo, 2012. Disponível em: <https://www.revistaensinosuperior.gr.unicamp.br/artigos/ acesso-ao-ensino-superior-no-brasil-equidade-e-desigualdade-social>. Acesso em: 05 nov. 2017.

BRASIL. Lei $\mathbf{n}^{\circ} \mathbf{7 . 4 9 8 / 8 6}$ de 25 de junho de 1986. Dispõe sobre a regularização do exercício de enfermagem e dá outras providencias. Brasília, 1986. Disponível em: <http://www.planalto.gov.br/ccivil_03/leis/L7498.htm>. Acesso em: 05 nov. 2017.

BRASIL. Ministério da Saúde. Secretaria de Atenção à Saúde. Portaria $\mathbf{n}^{\circ}$ 371, de 7 de maio de 2014. Institui diretrizes para a organização da atenção integral e humanizada ao recém- nascido (RN) no Sistema Único de Saúde(SUS). Brasília, 2014. Disponível em: <http://pesquisa.in.gov.br/imprensa/jsp/visualiza/index. jsp? jornal=1 \&pagina $=50 \&$ data=08/05/2014>. Acesso em: 05 nov. 2017. 
BRASIL. Ministério da Saúde. Diretriz Nacional de Assistência ao Parto Normal. Relatório de recomendação. Brasília, 2016. Disponível em: < http://conitec.gov.br/images/ Consultas/2016/Relatorio_Diretriz-PartoNormal_CP.pdf>. Acesso em: 05 nov. 2017.

CAGNIN, E. R. J.; MAMEDE, M. V.; MAMEDE, F. V. Atenção qualificada ao trabalho de parto: um estudo descritivo. Revista de enfermagem UFPE online, v.8, n. 10, p. 3266$3274,2014$.

CUNNINGHAM, F. G.; LEVENO, K. J.; BLOOM, S. L. Williams Obstetrics. 23 ed. New York: McGraw-Hill, 2010.

DELPISHEH, A. et al. Pregnancy late in life: a hospital: based study of birth outcomes. Journal of women's health, v. 17, n.6, p. 965-970, 2008.

FERREIRA, A. G. N. et al. Humanização do parto e nascimento: acolher a parturiente na pespectiva dialógica de Paulo Freire. Rev enferm UFPE on line, v. 7, n.5, p. 13981405, 2013. Doi:10.5205/revol.3960-31424-1-SM.0705201319

GOMES, A. R. M. et al. Assistência de enfermagem obstétrica na humanizaççao do parto normal. Revista Recien, v. 4, n. 11, p. 23-27, 2014. http://dx.doi.org/10.24276/ rrecien2358-3088.2014.4.11.23-27

GONÇALVES, R. et al. Vivenciando o cuidado no contexto de uma casa de parto: o olhar das usuárias. Revista escola enfermagem, v. 45, n. 1, p. 62-70, 2011.

JAMAS, M. T.; HOGA, L. A. K.; TANAKA, A. C. A. Mother's birth care experiences in Brazilian birth centr. Midwifery, v. 27, n.1, P. 693-699, 2011.

MPPE - Ministério Público de Pernambuco. Humanização do parto. Nasce o respeito: informações práticas sobres seus direitos / Organização, Assessoria Ministerial de Comunicação; Coordenação, M. S. M. O; Redação, A. C. R. C.; M. M. O. Revisão Técnica, Comitê Estadual de Estudos de Mortalidade Materna de Pernambuco. -- Recife: Procuradoria Geral de Justiça, 2015. Disponível em: <http://www.mppe. $\mathrm{mp} . \mathrm{br} / \mathrm{mppe} /$ attachments/article/4240/cartilha\%20humanizacao\%20do\%20 parto\%20pdf.pdf>. Acesso em: 05 nov. 2017.

NAGAHAMA, E. E. I.; SANTIAGO, S. M. Parto humanizado e tipo de parto: avaliação da assistência oferecida pelo Sistema Único de Saúde em uma cidade do sul do Brasil. Revista Brasileira de Enfermagem Materno Infantil, v. 11, n. 4, p. 415-425, 2011.

SALARI, Z. et al. Late umbilical cord clamping, neonatal hematocrit and Apgar scores: A randomized controlled trial. Journal or neonatal-Perinatal Medicine, v. 7, n. 4, p. 287-291, 2014. 
SILVA, R. S.; CAMPOS, A. E. R.; PEREIRA, A. Caring for the patient in the process of dying at the intensive care unit. Rev Esc Enferm USP. v. 45, n. 3, p. 735-40, 2011.

SILVA, A. L. A. et al. Avaliação da assistência hospitalar materna e neonatal: índice de completude da qualidade. Rev Saúde Pública, v. 48, n. 4, p. 682-691, 2014.

IBGE - Instituto Brasileiro de Geografia e Estatística. Indicadores sociais sobre a mulher. 2017. Acesso em: <https://www.ibge.gov.br>. Disponível em: 05 nov. 2017.

VICTORA et. al. Breastfeeding in the 21 st century: epidemiology, mechanisms, and lifelong effect. The Lancet. Disponível em: < https://repositorio.bc.ufg.br/tede/bitstream/ tede/7368/5/Disserta\%C3\%A7\%C3\%A30\%20-\%20Romilda\%20Rayane\%20Godoi\%20Souza\%20 -\%202017.pdf.>. Acesso em: 04 Nov. 2017.

VICTORA, C. G. et al. Breastfeeding in the 21 st century: epidemiology, mechanisms, and lifelong effect. The Lancet, v. 387, n. 10017, p. 475-490, 2016.

WHO - WORLD HEALTH ORGANIZATION. WHO statement on Caesarean section rates. 2015. Disponível em: < http://www.who.int/reproductivehealth/publications/ maternal_perinatal_health/cs-statement/en/>. Acesso em: 04 nov. 2017.

ZUSE, C. L.; BRIGO, L.; SILVA, M. B. Diagnósticos e intervenções de enfermagem para pacientes das clínicas médica e cirúrgica de um hospital geral: relato de experiência.

Vivências Erechim, v. 6, n. 9, 2010.

Recebido em: 08/05/2018.

Aceito em: 13/05/2019. 